\title{
Chylous Leakage Post-mastectomy and Axillary Dissection
}

\author{
Matheka Mwongeli, Ronald Wasike
}

Faculty of Health Sciences East Africa-Surgery, Aga Khan University Hospital, Nairobi

Correspondence to: Dr. Matheka Mwongeli; email: mathekamail@gmail.com

Received: 28 October 2019; Revised: 15 August 2020; Accepted: 19 August 2020; Available online: 1

September 2020

\section{Summary}

Chylous leakage is a rare complication following mastectomy and axillary dissection. We report a case of a 46-year-old female who underwent modified radical mastectomy and developed chylous leakage. She was treated successfully with conservative management. Keywords: Chylous leakage, chyle, mastectomy, axillary dissection
Ann Afr Surg. 2021; 18(2): 123-125

DOI: http://dx.doi.org/10.4314/aas.v18i2.12

Conflicts of Interest: None

Funding: None

(C) 2021 Author. This work is licensed under the

Creative Commons Attribution 4.0 International

License.

\section{Introduction}

Chylous leakage, although rare, usually follows neck dissection or thoracic surgery and is not normally seen following breast and axillary surgery (1). It occurs as a result of injury to the aberrant branches of the thoracic duct (2). Diagnosis is often made clinically from the appearance of milky white fluid in the drain.

Laboratory tests may be done in case of uncertainty to confirm the diagnosis (3). Conservative management with continuous drainage, a low-fat diet, and octreotide is usually sufficient. However, some cases may require surgical management (4). A literature search on PubMed with the terms "chyle" AND "breast" OR "axilla" found no reports or literature from Africa. Here, we present a case of chyle leakage post-mastectomy and axillary dissection that we managed conservatively.

\section{Case report}

The patient gave consent to report this case report and to use the images. Institutional ethical approval was also obtained. A 46-year-old female presented with pleomorphic microcalcifications in her left breast seen on a routine screening mammogram. A stereotactic biopsy showed ductal carcinoma in situ (DCIS). Due to the diffuse pattern of the microcalcifications spanning an area of more than 5 $\mathrm{cm}$, she was planned for mastectomy. Although she was a candidate for sentinel lymph node biopsy, the institutional gamma probe was out of order. Therefore, she underwent a left modified radical mastectomy. A level II axillary dissection was done and a drain was placed in the wound. Her postoperative period was uneventful until day 2 post-surgery when she was noted to have a milky white discharge from the drain. Triglyceride levels of the fluid were $219 \mathrm{mmol} / \mathrm{L}$ (reference range $0.3-1.7 \mathrm{mmol} / \mathrm{L}$ ), which confirmed chylous drainage. The drain output was initially $313 \mathrm{~mL}$ in $24 \mathrm{~h}$. She was started on a low-fat diet and octreotide $50 \mu \mathrm{g}$ subcutaneously (SC) every $8 \mathrm{~h}$. The drain output reduced gradually. Drainage on postoperative day 6 was $120 \mathrm{~mL}$ and she was discharged home with the drain.

She was followed up in the breast clinic a week later and drainage had reduced to $54 \mathrm{~mL} /$ day. The drain was removed on postoperative day 18 when it was draining less than $50 \mathrm{~mL} /$ day. Histology confirmed DCIS grade 3 with 11 out of 11 nodes negative. 


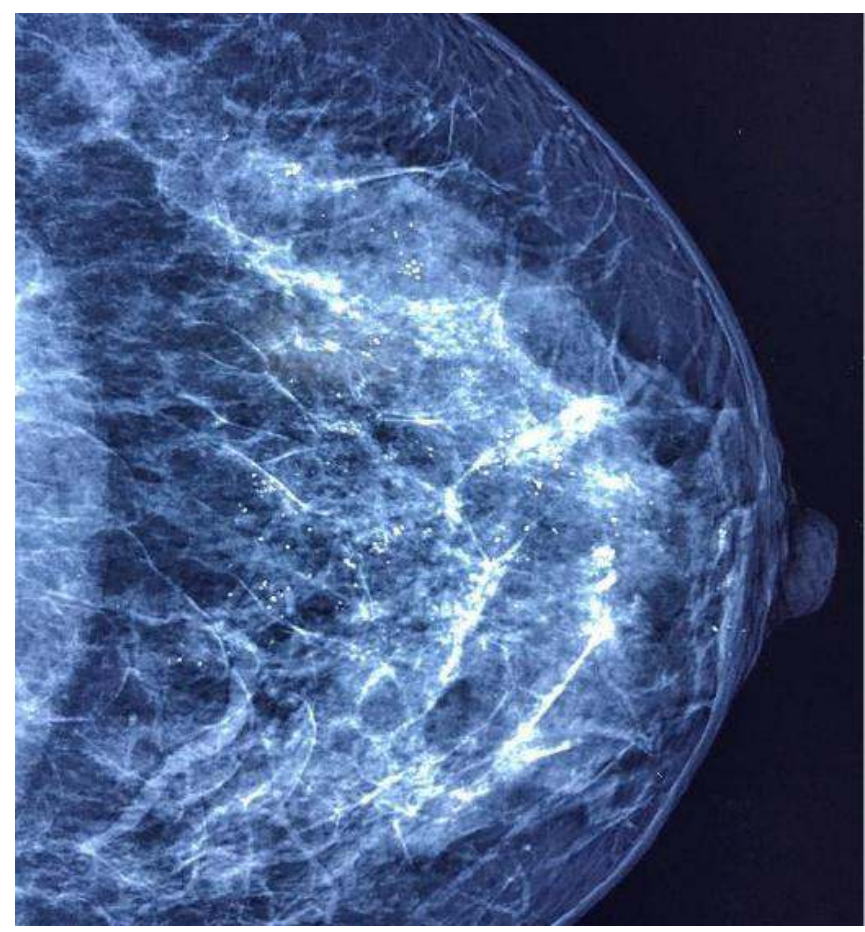

Figure 1. Mammogram craniocaudal view of the left breast showing diffuse microcalcifications spanning more than $5 \mathrm{~cm}$

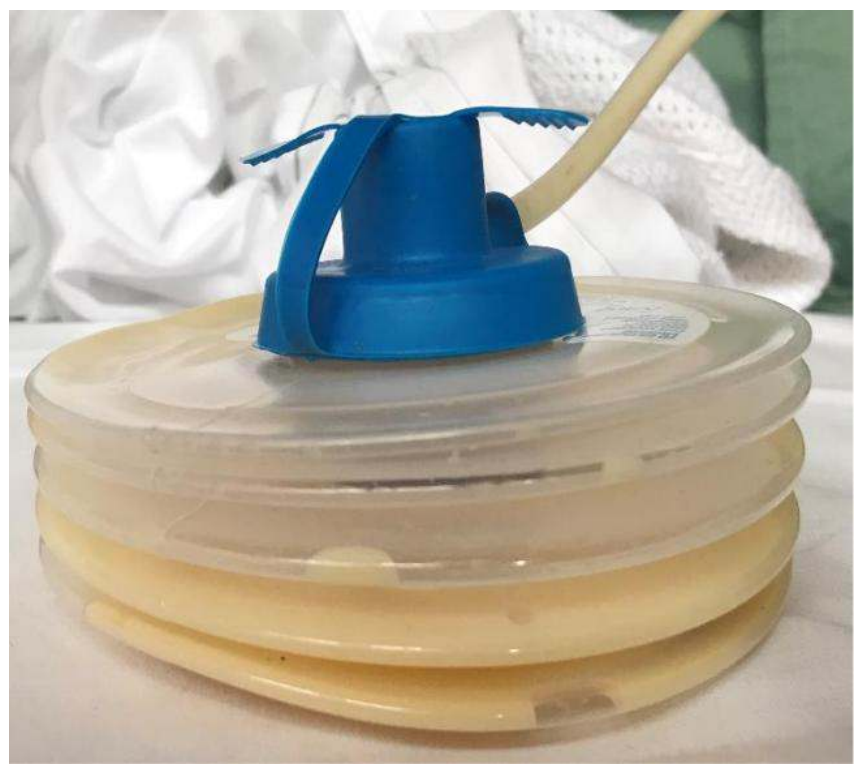

Figure 2. Milky white fluid from the drain characteristic of chyle

\section{Discussion}

Chylous leakage is a rare complication post axillary dissection. Nakajima et al. reported 4 cases out of 851 patients undergoing breast cancer surgery, an incidence of $0.4 \%$ (1). Similar studies have reported incidence of $0.36-0.68 \%(5,6)$. A systematic review of 51 reported cases of chylous leakage post axillary dissection by Farkas et al. found that $92 \%$ of the cases were on the left side. Eighty-two percent of the patients had undergone level II or III axillary lymph node dissection with five patients undergoing sentinel lymph node biopsy. Similar to our patient, $59 \%$ of the leaks were identified on day 2 post-surgery. Ninety-six percent were managed conservatively, initially with $22 \%$ requiring surgical intervention after failure of conservative management. Our patient's drain was removed on day 18 post-surgery, which corresponds to the mean time to resolution from initial surgery reported of 17.3 days (7).

The thoracic duct and its branches are rarely encountered in the axilla and therefore injury is uncommon. However, anatomic variations in the branches of the thoracic duct occur and predispose to injury during axillary surgery.

The thoracic duct is the main lymphatic vessel that transports lymph from $75 \%$ of the body back into the venous system. The thoracic duct originates at the cisterna chyli at L2-T12 from the confluence of the left lumbar and intestinal lymphatic trunks. It ascends into the thorax through the aortic aperture in the diaphragm and runs on the right side of the vertebrae, ventral to the aorta, up to the level of T6 where it crosses over to the left side. Here it runs posterior to the esophagus up to the junction of the internal jugular and subclavian vein, where it terminates (8). Several anatomic variations in the termination of the thoracic duct have been found: Type A (38\%) at the venous angle, Type B (28\%) at the internal jugular vein, Type C (27\%) at the external jugular vein, and Type D (7\%) in a complex configuration. The thoracic duct is often separated into two to three branches before draining into the vein (9). A study of 334 lymphoscintigraphy results showed two cases $(0.6 \%)$ draining into the left axilla (2). Therefore, injury to an aberrant branch of the thoracic duct during axillary dissection could lead to a chylous leak. 
Chylous leakage is often diagnosed clinically from the classical appearance of milky white fluid in the drain. This is often noted on the first or second postoperative day, following resumption of normal diet containing fats (10). Diagnosis can be confirmed by lipid, protein, cell count, and $\mathrm{pH}$ levels in the fluid. Triglyceride levels $>110 \mathrm{mg} / \mathrm{mL}$ are diagnostic of chyle (3). Lymphoscintigraphy is also a useful adjunct in localizing the chylous leak when surgical intervention is required (11). Management of chylous leakage is often conservative. The patient is put on a low-fat diet $(<10 \mathrm{~g}$ of fat/day), with pressure dressing and negative pressure drainage. Octreotide may be given to reduce chyle output. This is a somatostatin analogue which reduces absorption of triglycerides, reduces splanchnic blood flow, and reduces intestinal motility, therefore reducing lymph flow (12). Local injection with tetracycline hydrochloride has also been used in chyle leakage following neck dissection. However, high output leakage more than $700 \mathrm{~mL} /$ day or persistent leakage beyond 2 weeks may require surgical intervention. The injured branches of the thoracic duct may be ligated or embolized (4).

We acknowledge that for widespread DCIS, mastectomy plus sentinel lymph node biopsy should have been done instead of an axillary dissection due to a low positive nodal rate of $1 \%$ (13). However, due to technical difficulties, an axillary lymph node dissection was performed for this patient.

\section{Conclusion}

Although a rare complication, it is important to be aware of possible chylous leakage post axillary dissection. Diagnosis can be made clinically and management is often conservative.

\section{References}

1. Nakajima E, Iwata H, Iwase $\mathrm{T}$, et al. Four cases of chylous fistula after breast cancer resection. Breast Cancer Res Treat. 2004;83(1):11-14.

2. Bourgeois P, Munck D, Sales F. Anomalies of thoracic lymph duct drainage demonstrated by lymphoscintigraphy and review of the literature about these anomalies. Eur $\mathrm{J}$ Surg Oncol. 2008;34(5):553-555.
3. Maldonado F, Hawkins FJ, Daniels CE, et al. Pleural fluid characteristics of chylothorax. Mayo Clin Proc. 2009;84(2):129-133.

4. Daggett J, Watt A, Smith P. Chyle leak following right axillary lymph node dissection: A case report and review of current literature. Int J Surg Case Rep. 2016; 20:68-73.

5. Cong M, Liu Q, Zhou W, et al. Six cases of chylous leakage after axillary lymph node dissection. Oncol Res Treat. 2008;31(6):321-324.

6. Zhou W, Liu Y, Zha X, et al. Management of chylous leakage after breast surgery: Report of four cases. Surg Today. 2011;41(12):1639.

7. Farkas N, Wong J, Monib S, et al. A systematic review of chyle leaks and their management following axillary surgery. Eur J Surg Oncol. 2020;46(6):931-942.

8. Phang K, Bowman M, Phillips A, et al. Review of thoracic duct anatomical variations and clinical implications. Clin Anat. 2014;27(4):637-644.

9. Shimada K, Sato I. Morphological and histological analysis of the thoracic duct at the jugulo-subclavian junction in Japanese cadavers. Clin Anat. 1997;10(3):163172.

10. Taylor J, Jayasinghe S, Barthelmes L, et al. Chyle leak following axillary lymph node clearance - a benign complication: Review of the literature. Breast Care. 2011;6(2):130-132.

11. Bender B, Murthy V, Chamberlain RS. The changing management of chylothorax in the modern era. Eur $\mathrm{J}$ Cardiothorac Surg. 2015;49(1):18-24.

12. Swanson MS, Hudson RL, Bhandari N, et al. Use of octreotide for the management of chyle fistula following neck dissection. JAMA Otolaryngol. 2015;141(8):723727.

13. Winchester DP, Menck HR, Osteen RT, et al. Treatment trends for ductal carcinoma in situ of the breast. Ann Surg Oncol. 1995;2(3):207-13. 